\title{
Concise and Stereoselective Total Syntheses of Annotinolides C, D, and E
}

Pei Qu and Scott A. Snyder*

Department of Chemistry, The University of Chicago, 5735 S. Ellis Ave, Chicago, IL 60637

Abstract. The annotinolides are one of the most recent additions to the Lycopodium family of alkaloids, with its members possessing challenging, caged structures that include a [3.2.1]-bicyclic core bearing six contiguous stereocenters, including oxa-, aza-, and allcarbon quaternary centers. Herein, we document a concise and stereoselective route that achieves the first total syntheses of three of its members: annotinolides C, D, and E. Key operations include a gold(I)-catalyzed Conia-ene reaction that fashions much of the main core in a single operation, as well as a number of other challenging and chemoselective transformations to generate the remaining elements. Moreover, efforts utilizing the natural products themselves, seeking adjustments in their oxidation states and the rearrangement of individual ring systems, sheds light on their potential biogenesis with some outcomes counter to those originally proposed. Finally, formal enantioenriched syntheses of the target molecules are also presented.

In 2016, Zhang, $\mathrm{Hu}$, and co-workers reported the isolation and characterization of a unique collection of alkaloid-based natural products from Lycopodium annotinium, including 1-3 (Scheme 1). ${ }^{1}$ While structurally related to the famous lycopodine family, of which $\mathbf{4}$ is the flagship member given its historic isolation in 1881,2 these compounds possess a truncated and more highly oxidized [3.2.1]-bicyclic core in contrast to the standard [3.3.1]framework of the parent class. This domain within the annotinolides, while generally rare, has been found in other alkaloid classes as exemplified by the structures of gelsemine (5) ${ }^{3}$ and isopalhinine A (6), ${ }^{4}$ and can be quite challenging to fashion as revealed by published syntheses of these particular targets over the past decade. For 1-3 specifically, this [3.2.1]bicycle leads to the presence of 6 contiguous chiral centers within the main core, of which 3 are fully substituted, with 1 being an all-carbon quaternary center (with the C-12 and C-15 centers exhibiting increased oxidation states versus 4). The remaining structural variations among the drawn annotinolides reflect further changes in oxidation state and/or peripheral ring patterning. To date, no member of this collection has succumbed to laboratory synthesis, with only a recent model study by Tu illustrating a potential approach to fashion their common core. ${ }^{5}$ Herein, we report the first route capable of achieving their total syntheses through a cohesive strategy featuring several carefully orchestrated transformations to both fashion and manipulate their structural elements despite their intricate and sterically encumbered environments. Additionally, a series of chemical operations performed on the synthesized natural products offers insights into their biosynthetic relationships, in one case suggesting a connection counter to the original biogenetic proposals posited by the isolation team. Finally, a formal asymmetric synthesis of a key building block is presented. 
Scheme 1. Structures of selected annotinolides possessing a challenging [3.2.1]-bicyclic core shared with other alkaloids and a strategy to achieve their laboratory synthesis.

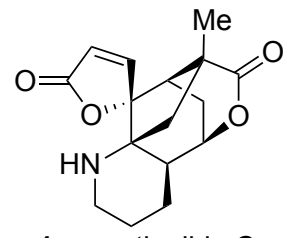

1: annotinolide C

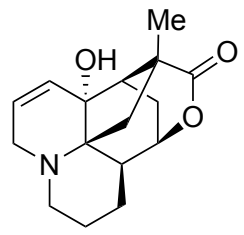

2: annotinolide D

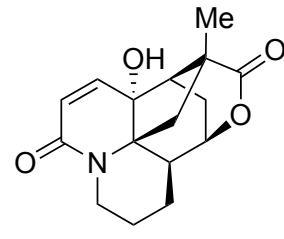

3: annotinolide $\mathrm{E}$

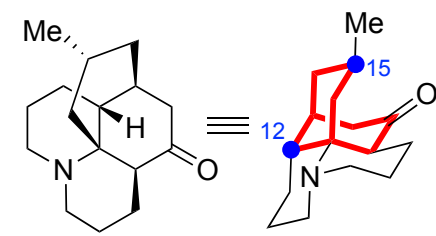

4: lycopodine

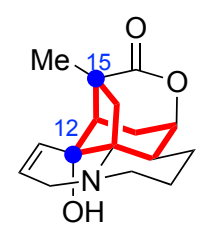

2: annotinolide D

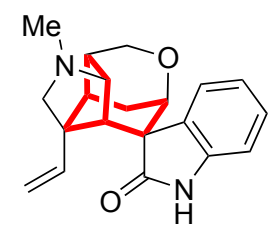

5: gelsemine

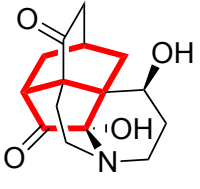

6: isopalhinine A<smiles>CC12CCC3(CCCC(C3)C13C=CC(=O)N3)OC2=O</smiles>

1: annotinolide $\mathrm{C}$

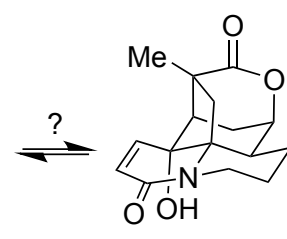

3: annotinolide $\mathrm{E}$

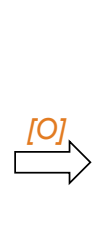

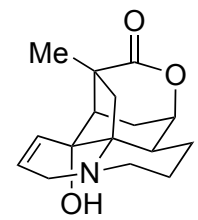

2: annotinolide D

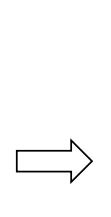

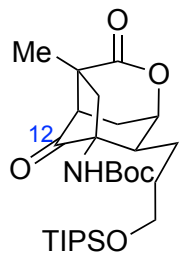

7
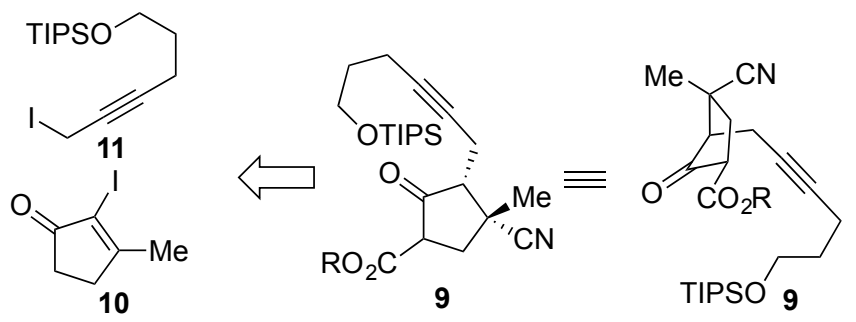

[Amination]
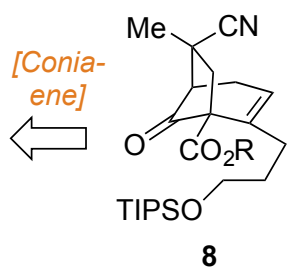

Our general strategy, shown in the lower half of Scheme 1, sought a unified approach wherein we could potentially interconvert a given family member into another. Thus, we anticipated annotinolide E (3) may be derived from annotinolide D (2) through an allylic oxidation, and that annotinolides C (1) and E (3) might be able to interconvert under appropriate conditions between their respective lactam and lactone forms. Whether one variant would be preferred over the other and/or whether they might exist in equilibrium was unknown, noting that the isolation team proposed that annotinolide E (3) may arise from annotinolide D (2). ${ }^{1 a}$ However, no experimental or computational support for that assertion was provided. Next, if the remaining elements of their ring systems outside of the core [3.2.1]-bicycle were excised, projecting their late-stage incorporation, we then arrived at goal structure 7. Here, we hoped that the core elements could arise readily from a far simpler cyclopentanone derivative (9) as a result of three main operations: 1) a lactonization onto a precursor alkene (using a carboxylic acid derived from a nitrile), 2) conversion of the ester within $\mathbf{8}$ into an amine through a Curtius or related rearrangement, ${ }^{6}$ and 3 ) a Conia-ene reaction ${ }^{7}$ to sew up the main bicyclic core. In these 
events, the formation of each new chiral center in the core, including those that are fully substituted, would be governed by the nitrile-containing all-carbon quaternary center found within 9.8 That intermediate might in turn arise from a diastereoselective vicinal difunctionalization of cyclopentenone $\mathbf{1 0 .}$

Our efforts commenced with the preparation of the substrate needed for the key Conia-ene step, starting with the merger of iodide $\mathbf{1 1}$ (prepared in 3 steps, ${ }^{9}$ see Supporting Information) and known cyclopentenone 10 (Scheme 2). ${ }^{10}$ That operation, facilitated by the use of $i$ - $\mathrm{PrMgCl}$ and $\mathrm{CuCN} \cdot 2 \mathrm{LiCl}$ using Knochel's procedure, ${ }^{11}$ proceeded smoothly in $81 \%$ yield to afford 13 . Then, similar to Huet's protocol,12 we achieved a synthesis of the 1,4-cyano addition product 14 in 68\% yield using in situ-generated Nagata's reagent; in this event, the initially obtained silyl enol ether was cleaved under an HCl-promoted work-up to afford the desired (and likely thermodynamically favored) trans-relationship between the original methyl group and propargyl sidechain of 13. Next, treatment with LDA followed by Mander's reagent $\left(\mathrm{NCCO}_{2} \mathrm{Me}\right)$ afforded 1,3-dicarbonyl 15 in $64 \%$ yield as an inconsequential mixture of diastereomers about the newly-formed chiral center.

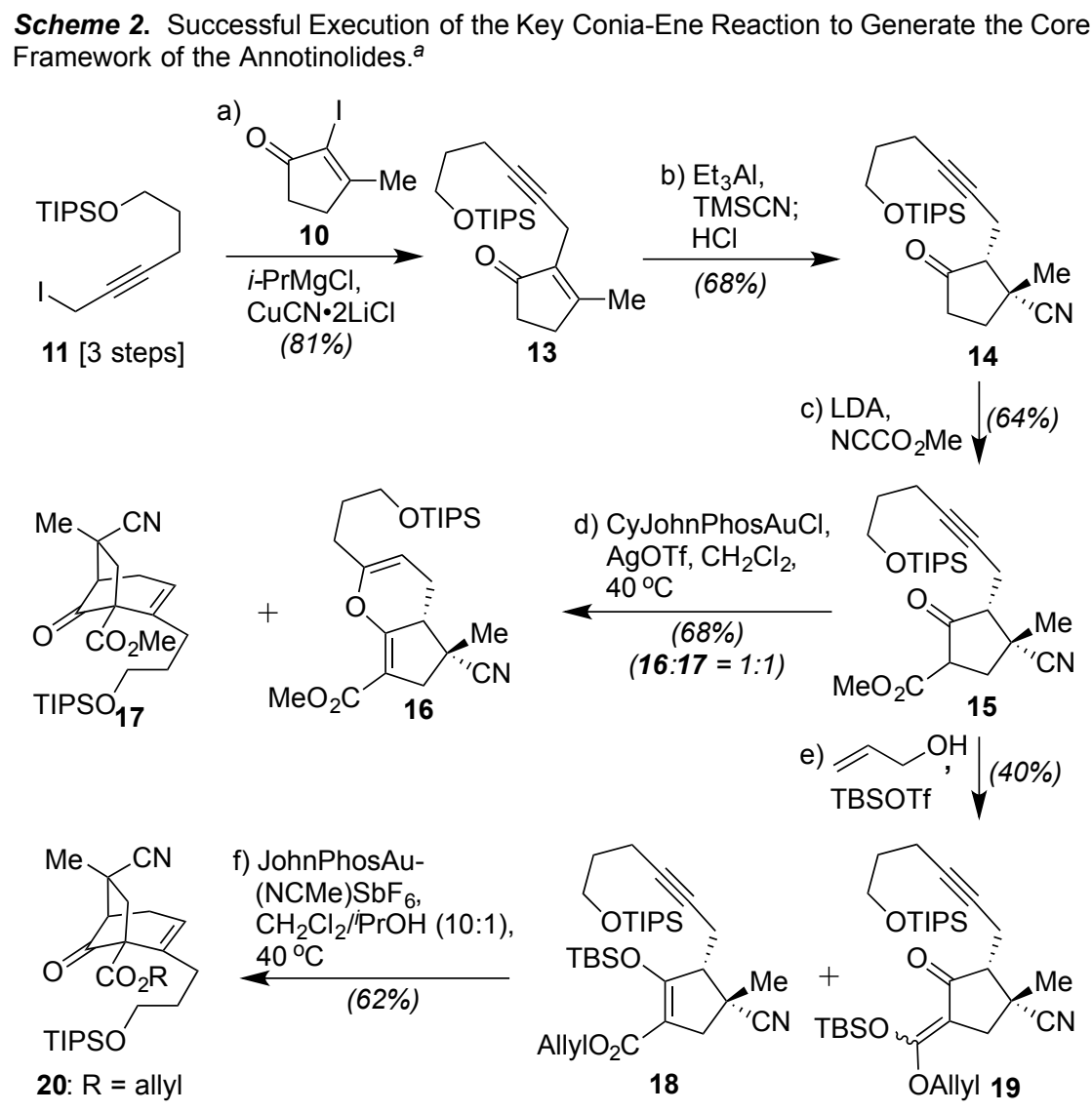

${ }^{a}$ Reagents and conditons: (a) 10 (1.5 equiv), $i-\mathrm{PrMgCl}$ (1.5 equiv), $\mathrm{CuCN} \cdot 2 \mathrm{LiCl}(1.5$ equiv), THF (0.12 M), -78 to $23^{\circ} \mathrm{C}, 1.5 \mathrm{~h}, 81 \%$; (b) $\mathrm{Et}_{3} \mathrm{Al}$ (1.2 equiv), TMSCN (2.2 equiv), hexanes $(0.1 \mathrm{M}), 60^{\circ} \mathrm{C}, 1 \mathrm{~h}$, then THF/3 N HCl $=4: 1(0.3 \mathrm{M}), 23^{\circ} \mathrm{C}, 10 \mathrm{~min}, 68 \%$; (c) LDA (2.1 equiv), $\mathrm{NCCO}_{2} \mathrm{Me}\left(1.5\right.$ equiv), THF $(0.1 \mathrm{M}),-78{ }^{\circ} \mathrm{C}, 1.5 \mathrm{~h}, 64 \%$; (d) CyJohnPhosAuCl (0.2 equiv), AgOTf (0.2 equiv), $\mathrm{CH}_{2} \mathrm{Cl}_{2}, 40^{\circ} \mathrm{C}, 24 \mathrm{~h}$; (e) toluene/allyl alcohol $=4: 1(0.1 \mathrm{M}), 110{ }^{\circ} \mathrm{C}, 3 \mathrm{~h}$, then Hunig's base (5.0 equiv), TBSOTf (2.0 equiv), $\mathrm{CH}_{2} \mathrm{Cl}_{2}(0.1 \mathrm{M}), 0.5 \mathrm{~h}, 40 \%$; (f) JohnPhosAu(NCMe)SbF 6 (0.3 equiv), $\mathrm{CH}_{2} \mathrm{Cl}_{2} / \mathrm{iPrOH}=$ $10: 1(0.1 \mathrm{M}), 40^{\circ} \mathrm{C}, 48 \mathrm{~h}, 62 \%$. 
With this critical material in hand, efforts to complete the [3.2.1]-core through a Conia-ene reaction commenced. In practice, this event proved quite challenging to achieve cleanly. Although initial explorations revealed that bicycle $\mathbf{1 7}$ could be fashioned from $\mathbf{1 5}$ using appropriate promoters, ${ }^{13}$ the best result obtained after extensive screening was a $1: 1$ mixture of both the desired $\mathbf{1 7}$ and the $O$-cyclization product $\mathbf{1 6}$ in a combined yield of $68 \%$ (Scheme 2). That outcome was achieved using $20 \mathrm{~mol} \% \mathrm{CyJohnPhosAuCl}$ in the presence of $20 \mathrm{~mol} \%$ AgOTf in refluxing $\mathrm{CH}_{2} \mathrm{Cl}_{2}$ over the course of $24 \mathrm{~h}^{7 \mathrm{c}}$ Unfortunately, despite this partial success, subsequent efforts to selectively hydrolyze the methyl ester within $\mathbf{1 7}$ to set the stage for an eventual Curtius rearrangement proved fruitless, affording only decomposition instead. Given these collated issues, we wondered whether execution of the Conia-ene reaction using a silyl enol ether precursor with a different ester analog might prove superior. Pleasingly, such a substrate could be fashioned in a single step by stirring 15 with allyl alcohol in refluxing toluene ${ }^{14}$ followed by exposure to Hünig's base and TBSOTf. This operation afforded an inseparable mixture of $\mathbf{1 8}$ and 19, both of which could then be smoothly converted into [3.2.1]-bicycle 20, the allyl ester variant of $\mathbf{1 7}$, in $62 \%$ overall yield. For this Conia-ene transformation, the optimal conditions proved to be treatment with JohnPhosAu(NCMe) $\mathrm{SbF}_{6}$ in the absence of an added $\mathrm{Ag}(\mathrm{I})$ promoter, with the mixed solvent system ${ }^{7 \mathrm{c}}\left(\mathrm{CH}_{2} \mathrm{Cl}_{2} / \mathrm{i}-\mathrm{PrOH}=10: 1\right)$ being essential.

With the main framework secured, efforts shifted next to the structural alterations needed to both finalize the full core and its remaining appended ring systems; executing these operations and effecting certain transformations with proper diastereocontrol required both chemospecific and substrate-based solutions. First, although the ketone moiety within 20 was formally needed to realize the targets (vide infra), its presence inflicted undesirable instability within all related intermediates, thus requiring the $\mathrm{C}-12$ ketone to be stereospecifically reduced and protected over two steps to afford $\mathbf{2 1}$ (Scheme 3). Next, the allyl ester was selectively cleaved through the action of $\mathrm{Pd}\left(\mathrm{PPh}_{3}\right)_{4}$ and pyrrolidine, ${ }^{15}$ allowing for the highly hindered bridgehead aza-quaternary nitrogen center to then be forged through a Curtius rearrangement conducted under Fukuyama's conditions, ${ }^{16}$ delivering the Boc-protected amine 22. With an eye towards forming the bridged lactone of the annotinolides, the nitrile group was then converted into a carboxylic acid via a standard reduction/Pinnick oxidation sequence to afford $\mathbf{2 3}$ in 95\% overall yield. Despite the adamantine-like rigidity of this structure, subsequent efforts to directly promote lactonization onto the neighboring alkene using $\mathrm{Ag}(\mathrm{I})$ failed. ${ }^{17}$ Pleasingly, when this event was promoted instead with NIS in $\mathrm{CH}_{2} \mathrm{Cl}_{2}$ at $23{ }^{\circ} \mathrm{C}$, polycycle 24 could be formed smoothly (74\% yield).

The price for that facility, however, was the need to remove the target superfluous iodine atom within 24 and replace it, stereospecifically, with a hydrogen atom to retain the desired orientation of the alkyl sidechain at the same site. Unfortunately, while that deiodination could be readily achieved using $n-\mathrm{Bu}_{3} \mathrm{SnH}$ as promoted by $\mathrm{Et}_{3} \mathrm{~B}$ in air, the substrates' inherent preference for $\mathrm{H} \bullet$ recapture was entirely from the undesired face, affording 25 exclusively. Here, though, we hoped that if we removed the neighboring silicon protecting group to afford $\mathbf{2 6}$, the resultant alcohol might be able to afford the desired adduct from the same type of radical intermediate through an intramolecular 1,5hydrogen atom transfer. That supposition proved true, with compound $\mathbf{2 7}$ formed in near 
quantitative yield under commensurate deiodination conditions. Subsequent Dess-Martin oxidation then completed the assembly of core bicycle 7 in 93\% yield. As one reflection of the power of the overall Conia-ene/lactonization strategy to reach $\mathbf{7}$, we note that alternative modes of core closure, such as one attempting to utilize an oxidative coupling approach (shown here in the lower part of Scheme 3 with the conversion of 28 into 29) afforded only [3.3.1]-bicyclic adducts which could not, in our hands, be converted into the desired [3.2.1]-alternatives (i.e. 30).

Scheme 3. Completion of the [3.2.1]-Core of the Annotinolides. ${ }^{a}$
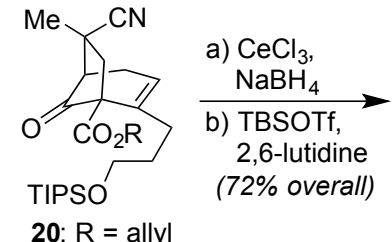

(72\% overall)

20: $\mathrm{R}$ = allyl

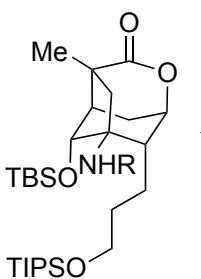

h) $n-\mathrm{Bu}_{3} \mathrm{SnH}$,

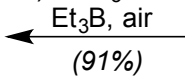

25: $\mathrm{R}=\mathrm{BOC}$
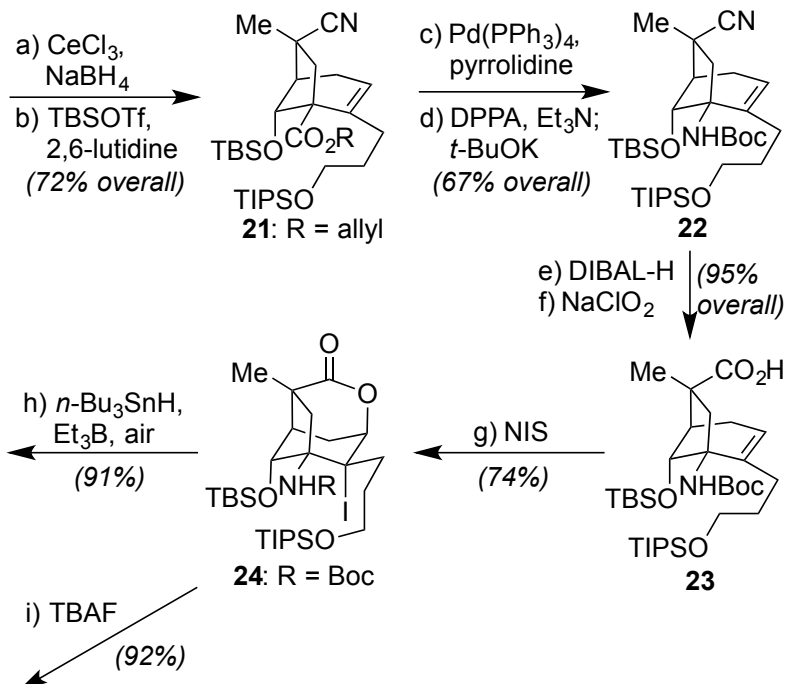

e) DIBAL-H $\mid(95 \%$

f) $\mathrm{NaClO}_{2}$ loverall)

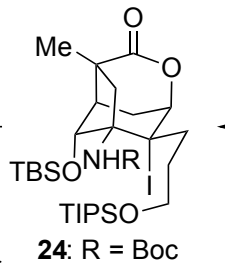

24: $R=B o c$

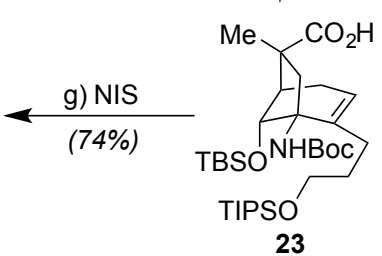

23
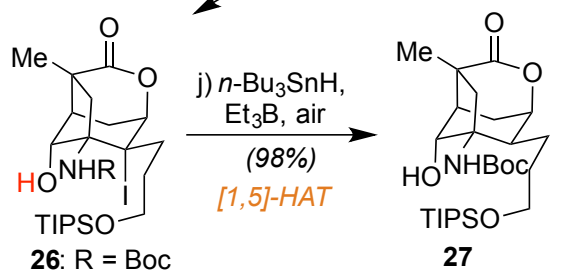

27
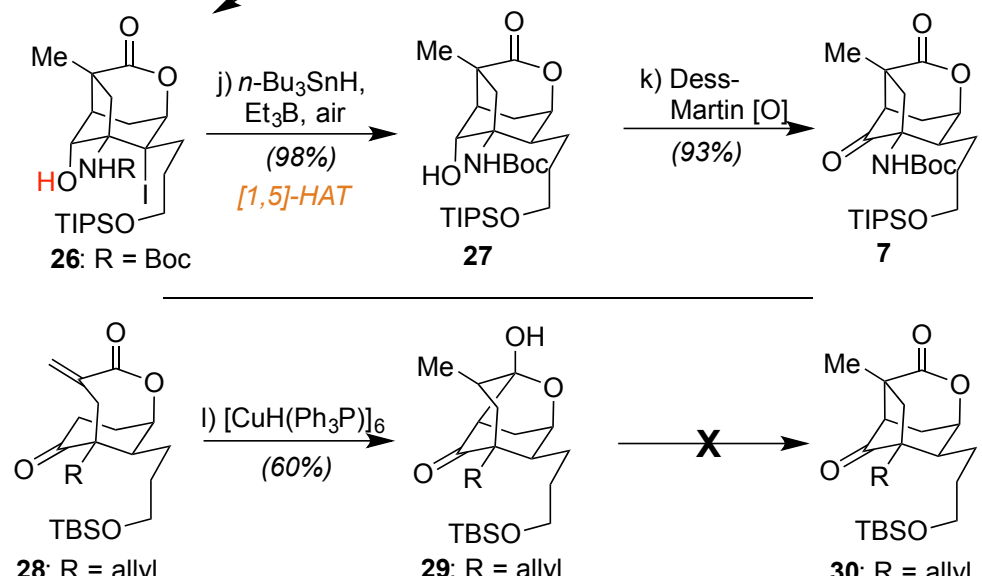

$\frac{\text { l) }\left[\mathrm{CuH}\left(\mathrm{Ph}_{3} \mathrm{P}\right)\right]_{6}}{(60 \%)}$

28: $R$ = allyl

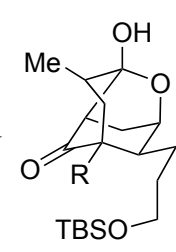

29: $R=$ allyl

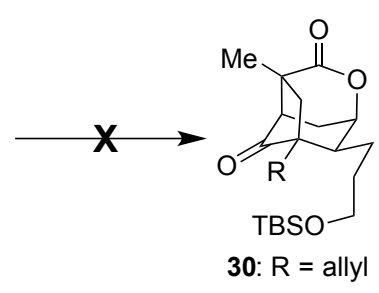

${ }^{a}$ Reagents and conditions: (a) $\mathrm{CeCl}_{3} \cdot 7 \mathrm{H}_{2} \mathrm{O}$ (1.2 equiv), $\mathrm{NaBH}_{4}$ (1.5 equiv), $\mathrm{MeOH}(0.1$ M), 0 to $23{ }^{\circ} \mathrm{C}, 0.5 \mathrm{~h}, 84 \%$; (b) 2,6-lutidine (5.0 equiv), TBSOTf (1.5 equiv), $\mathrm{CH}_{2} \mathrm{Cl}_{2}(0.1$ M), $23{ }^{\circ} \mathrm{C}, 4 \mathrm{~h}, 86 \%$; (c) $\mathrm{Pd}\left(\mathrm{PPh}_{3}\right)_{4}$ (0.4 equiv), pyrrolidine (1.2 equiv), MeCN (0.1 equiv), 0 to $23^{\circ} \mathrm{C}, 1 \mathrm{~h}, 82 \%$; (d) DPPA (1.0 equiv), $\mathrm{Et}_{3} \mathrm{~N}$ (2.0 equiv), toluene ( $\left.0.1 \mathrm{M}\right), 23$ ${ }^{\circ} \mathrm{C}, 0.5 \mathrm{~h}$; then $110^{\circ} \mathrm{C}, 1 \mathrm{~h}$; then $t$-BuOK $\left(2.0\right.$ equiv), $23^{\circ} \mathrm{C}, 1 \mathrm{~h}, 82 \%$; (e) DIBAL-H (4.0 equiv), toluene, $0{ }^{\circ} \mathrm{C}, 15 \mathrm{~min}$; (f) $\mathrm{NaH}_{2} \mathrm{PO}_{4} \cdot 2 \mathrm{H}_{2} \mathrm{O}$ (20 equiv), $\mathrm{NaClO}_{2}$ (10 equiv), $t$ $\mathrm{BuOH} / \mathrm{H}_{2} \mathrm{O} / 2$-methyl-2-butene = 3:3:1 (0.05 M), $23^{\circ} \mathrm{C}, 40 \mathrm{~min}, 95 \%$; (g) NIS (10 equiv), $\mathrm{CH}_{2} \mathrm{Cl}_{2}, 23^{\circ} \mathrm{C}, 6 \mathrm{~h}$; (h) $n-\mathrm{Bu}_{3} \mathrm{SnH}$ (1.5 equiv), $\mathrm{Et}_{3} \mathrm{~B}$ (1.0 equiv), air, toluene (0.05 M), 0 ${ }^{\circ} \mathrm{C}, 15 \mathrm{~min}, 91 \%$; (i) TBAF (1.0 equiv), THF $(0.1 \mathrm{M}), 0{ }^{\circ} \mathrm{C}, 15 \mathrm{~min}, 92 \%$; (j) $n-\mathrm{Bu}_{3} \mathrm{SnH}$ (1.5 equiv), $\mathrm{Et}_{3} \mathrm{~B}$ (1.0 equiv), air, toluene $(0.05 \mathrm{M}), 0{ }^{\circ} \mathrm{C}, 15 \mathrm{~min}, 98 \%$; (k) Dess-Martin periodinane (2.0 equiv), $\mathrm{NaHCO}_{3}$ (10.0 equiv), $\mathrm{CH}_{2} \mathrm{Cl}_{2}(0.05 \mathrm{M}), 23^{\circ} \mathrm{C}, 30 \mathrm{~min}, 93 \%$; (I) $\left[\mathrm{CuH}\left(\mathrm{Ph}_{3} \mathrm{P}\right)\right]_{6}\left(0.5\right.$ equiv), toluene $(0.5 \mathrm{M}), 23^{\circ} \mathrm{C}, 1 \mathrm{~h}, 60 \%$. 
From key intermediate 7, two members of the annotinolides were then completed through two final ring-forming processes as shown in Scheme 4. First, to access annotinolide D (2), an initial ring-closure was effected from 7 via silyl deprotection followed by a one-pot mesylate formation, Boc-removal, and intramolecular $\mathrm{S}_{\mathrm{N}} 2$ cyclization. The second ring closure proceeded through $N$-alkylation and an intramolecular, diastereoselective 1,2addition initiated by $t$-BuLi. These operations completed a 20 -step synthesis of this target from commercial materials, all of whose spectral data matched those reported by the isolation team. ${ }^{1 a}$ To access annotinolide C (1) from 7, this order of ring closures was reversed, with initial diastereoselective addition of lithium propiolate $34^{18}$ onto 7 followed by reduction with Lindlar's catalyst and addition of silica gel affording the lactone ring of 35. A similar desilylation $/ \mathrm{S}_{\mathrm{N}} 2$ ring-closure approach then completed this second target in 20-steps as well.

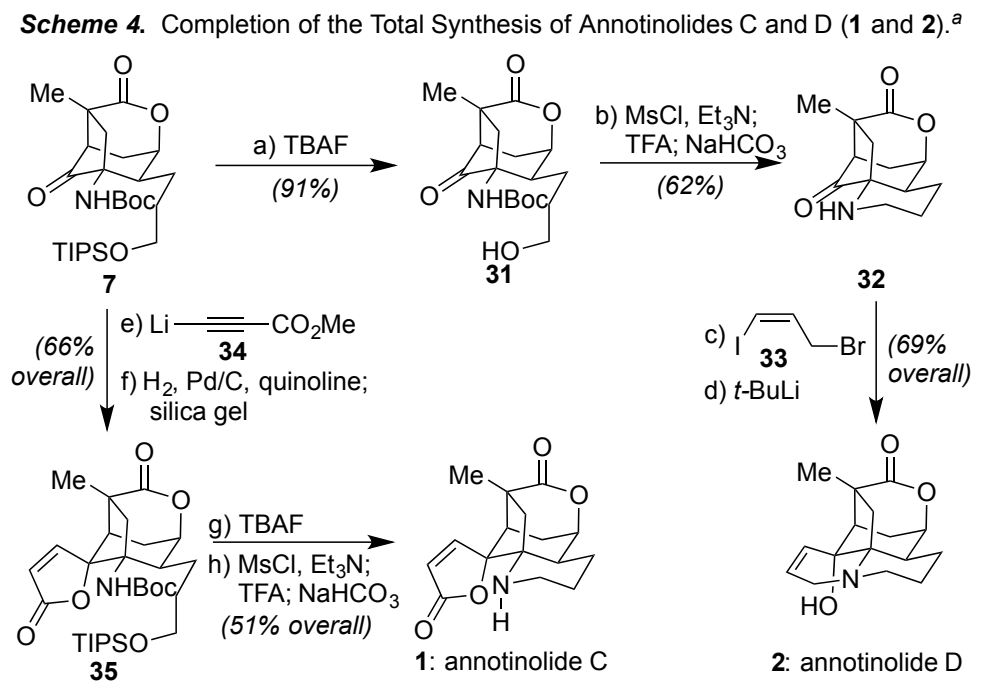

${ }^{a}$ Reagents and conditions: (a) TBAF (1.5 equiv), $\operatorname{THF}(0.05 \mathrm{M}), 0{ }^{\circ} \mathrm{C}$ to $23^{\circ} \mathrm{C}, 1 \mathrm{~h}, 91 \%$; (b) $\mathrm{MsCl}$ (3.0 equiv), $\mathrm{Et}_{3} \mathrm{~N}$ (10 equiv), $\mathrm{CH}_{2} \mathrm{Cl}_{2}(0.05 \mathrm{M}), 0^{\circ} \mathrm{C}, 0.5 \mathrm{~h}$; then $\mathrm{CH}_{2} \mathrm{Cl}_{2} \mathrm{TFA}=$ $4: 1(0.05 \mathrm{M}), 0{ }^{\circ} \mathrm{C}$ to $23^{\circ} \mathrm{C}, 1 \mathrm{~h}$; then $\mathrm{NaHCO}_{3}$ (excess), $23^{\circ} \mathrm{C}, 0.5 \mathrm{~h}, 62 \%$; (c) 33 (5.0 equiv), $\mathrm{K}_{2} \mathrm{CO}_{3}$ (10 equiv), MeCN ( $\left.0.1 \mathrm{M}\right), 23^{\circ} \mathrm{C}, 24 \mathrm{~h}, 87 \%$; (d) $t$-BuLi (2.1 equiv), THF (0.05 M), - $-78^{\circ} \mathrm{C}, 0.5 \mathrm{~h}, 79 \%$; (e) 34 (2.5 equiv), THF (0.05 M), $-78^{\circ} \mathrm{C}, 0.5 \mathrm{~h}, 84 \%$; (f) $\mathrm{Pd} / \mathrm{C}$ ( 0.1 equiv), quinoline (3.0 equiv), $\mathrm{H}_{2}$ (balloon pressure), $\mathrm{MeOH}(0.05 \mathrm{M}), 23{ }^{\circ} \mathrm{C}, 1$ $\mathrm{h}$; then silica gel $\left(1.0 \mathrm{~g} / \mathrm{mmol}\right.$ sub), $\mathrm{CH}_{2} \mathrm{Cl}_{2}(0.1 \mathrm{M}), 23{ }^{\circ} \mathrm{C}, 0.5 \mathrm{~h}, 78 \%$; $(\mathrm{g}) \operatorname{TBAF}(1.5$ equiv), THF (0.05 M), $23^{\circ} \mathrm{C}, 91 \%$; (h) $\mathrm{MsCl}$ (3.0 equiv), $\mathrm{Et}_{3} \mathrm{~N}$ (10 equiv), $\mathrm{CH}_{2} \mathrm{Cl}_{2}(0.05$ $\mathrm{M}), 0{ }^{\circ} \mathrm{C}, 0.5 \mathrm{~h}$; then $\mathrm{CH}_{2} \mathrm{Cl}_{2} / \mathrm{TFA}=4: 1(0.05 \mathrm{M}), 0{ }^{\circ} \mathrm{C}$ to $23^{\circ} \mathrm{C}, 1 \mathrm{~h}$; then $\mathrm{NaHCO}_{3}$ (excess), $23^{\circ} \mathrm{C}, 0.5 \mathrm{~h}, 56 \%$.

Critically, with these two targets in hand, we then explored our ability to interconvert them and access additional members. As expected, annotinolide D (2) could be oxidized into annotinolide E (3) with $\mathrm{KMnO}_{4}{ }^{19}$ in a 4:1 mixture of acetone and $\mathrm{H}_{2} \mathrm{O}$ proving optimal (Scheme 5). We then attempted to convert this new material into annotinolide C (1) based on the isolation team's hypothesis that its lactam could rearrange into a lactone.1a However, under all conditions attempted, we observed no such transformation, only recovered starting material. By contrast, when we exposed annotinolide C (1) to some of these conditions such as $\mathrm{NaOMe}$ in $\mathrm{MeOH}$, we could effect its partial conversion to annotinolide $\mathrm{E}$ (3, $\sim 67 \%$ conversion, 1:3 = 1:1 along with another unknown side product) after $1.5 \mathrm{~h}$ of stirring at $23^{\circ} \mathrm{C}$. Other bases, like triazobicyclodecene, ${ }^{20}$ could also achieve this conversion, but with inferior throughput (leading in this case to an $\sim 4: 1$ mixture of 1:3). Although we 
have not yet been able to effect complete conversion under any condition set, these findings to date suggest that $\mathbf{1}$ and $\mathbf{3}$ are not in equilibrium under basic conditions, and that $\mathbf{1}$ is potentially a viable biosynthetic precursor for $\mathbf{3}$, but the inverse is unlikely. ${ }^{21}$

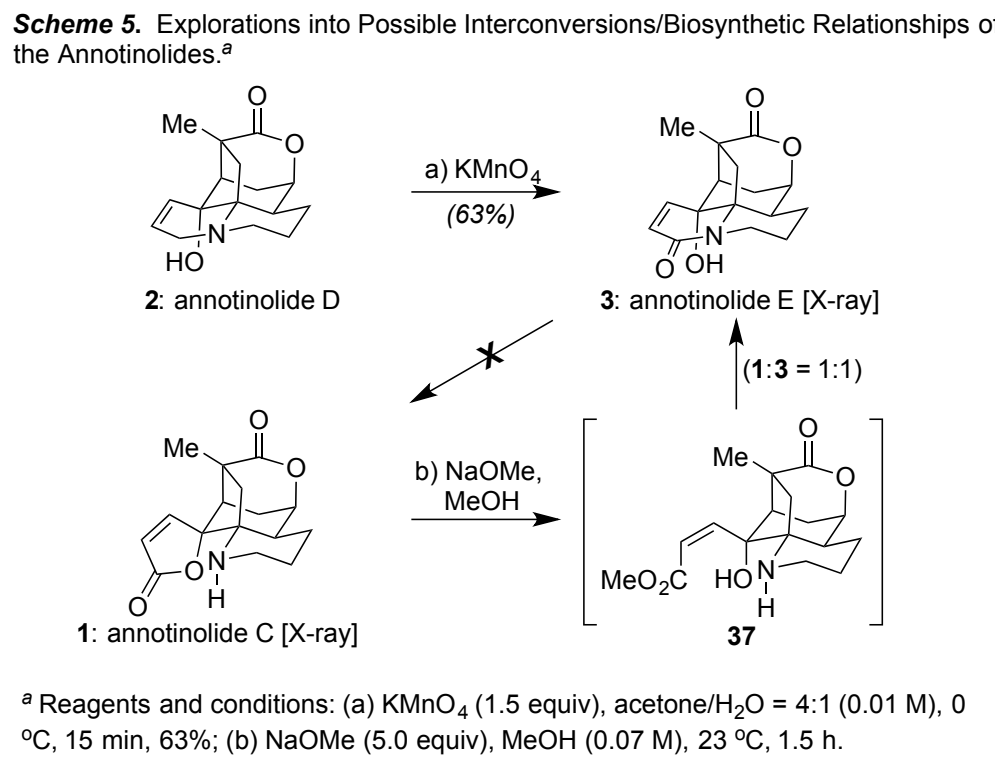

Finally, although our syntheses of the annotinolides were fully diastereoselective, the route presented above afforded racemic material. As a result, we also sought access to enantioenriched supplies of $\mathbf{1 5}$ to afford formal asymmetric syntheses. While simply stated, however, our requisite nitrile-containing all carbon-quaternary center was viewed as challenging to fashion as a single enantiomer given literature precedent. Indeed, both the Hesse ${ }^{22}$ and Herzon ${ }^{23}$ groups have shown that under basic conditions these centers in similar rings can both eliminate and/or racemize. Moreover, asymmetric methods to install such nitrile groups directly in a 1,4-fashion are arguably lacking; ${ }^{24}$ for example, as shown in Scheme 6 a recent asymmetric synthesis from the Qin group ${ }^{25}$ relied instead upon a $-\mathrm{CH}_{2} \mathrm{OPiv}$ group as a surrogate for such a cyanide, with substantive functional group changes needed to reach the desired material.

Thus, what we perceived as the most efficient approach was an enzymatic resolution. As shown, this idea worked with great facility following the generation of racemic 39 from $\mathbf{1 3}$, using lipozyme ${ }^{26}$ and the indicated acetate source to generate a separable mixture of $(+)-40$ and (-)-39 in near perfect yield and $e e$. The undesired acetate could be smoothly recycled to 13 through ester hydrolysis, alcohol oxidation, and base-promoted nitrile expulsion. By contrast, (-)-39 could be advanced into (-)-15 via oxidation and $\alpha$-esterification. Unfortunately, these latter processes both proceeded with some degree of racemization, with the oxidation affording an intermediate with a measured $e e$ value of $95 \%$ and the subsequent lithiation step eroding that further to $79 \%$ ee. Extensive screening of both operations (see SI for details) revealed that superior results could not be obtained. Pleasingly, though, chiral materials of commensurate ee values could be produced reliably and on scale through this general protocol. 


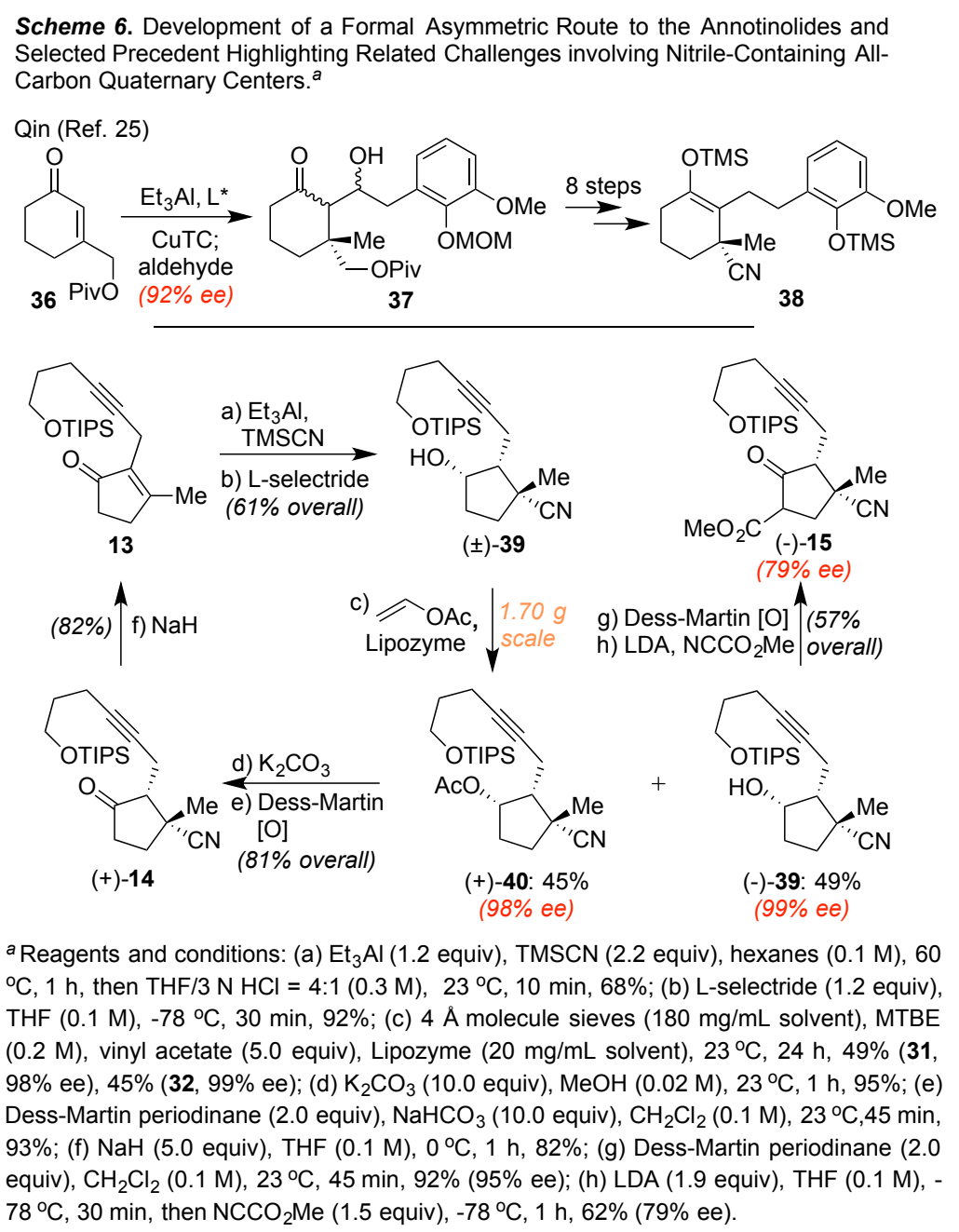

In conclusion, we have synthesized three members of the annotinolide family through an approach that leveraged the presence of an initial cyanide-containing quaternary center in a cyclopentanone precursor to stereospecifically fashion the remaining rings and chiral centers of these formidable caged compounds. Critical operations leading to that success include: 1) a challenging Conia-ene reaction to forge the entire [3.2.1]-core in a single operation using silyl enol ethers to circumvent alternate modes of cyclization, 2) subsequent use of the ester to generate a hindered aza-quaternary center through a Curtius rearrangement, 3) intramolecular 1,5-hydrogen atom transfer to finalize the core lactone motif, and 4) diastereoselective additions and terminating cyclizations to fashion the periphery. In addition, we established a viable means for the interconversion of two family members and developed a scalable route to access our key cyanide-containing building block in an enantioenriched fashion. Efforts to extend the lessons learned from these endeavors to other members of the family, as well as additional alkaloid classes, are the subject of current study. 


\section{Acknowledgments}

We thank Dr. Alexander Filatov, Dr. Andrew McNeece, and Ms. Kate Jesse for X-ray analysis of our crystalline intermediates (compounds 1, 3, and S7), and Dr. Josh Kurutz, Dr. Antoni Jurkiewicz, and Dr. C. Jin Qin for assistance with NMR and mass spectrometry, respectively. We also thank Ms. Josie Little for preliminary efforts directed towards optimizing the Conia-ene step. Financial support for this work came from the University of Chicago.

\section{References}

1. (a) Tang, Y.; Xiong, J.; Zhang, J.-J.; Zhang, W.; Zhang, H.-Y.; Hu, J.-F. Annotinolides A-C, Three Lycopodane-Derived 8,5-Lactones with Polycyclic Skeletons from Lycopodium annotinum. Org. Lett. 2016, 18, 4376. (b) Tang, Y.; Xiong, J.; Zou, Y.; Wang, W.; Huang, C.; Zhang, H.Y.; Hu, J.-F. Annotinolide F and lycoannotines A-I, further Lycopodium alkaloids from Lycopodium annotinum. Phytochemistry. 2017, 143, 1.

2. For the original isolation, see: (a) Bödeker, K. Lycopodin, das erste Alkaloïd der Gefässkryptogamen. Lieigs Ann. Chem. 1881, 208, 363. For the most recent reviews, see: (b) Siengalewicz, P.; Mulzer, J.; Rinner, U. Chapter 1: Lycopodium AlkaloidsSynthetic Highlights and Recent Developments. In The Alkaloids: Chemistry and Biology; Knölker, H.-J., Ed.; Academic Press: Cambridge, MA, 2013; Vol. 72, pp 1.

3. For the most recent synthetic study, see: (a) Tchabanenko, K.; Simpkins, N. S.; Male, L. A Concise Approach to a Gelsemine Core Structure using an Oxygen to Carbon Bridge Swapping Strategy. Org. Lett. 2008, 10, 4747. For the most recent total syntheses, see: (b) Earley, W. G.; Jacobsen, J. E.; Madin, A.; Meier, G. P.; O’Donnell, C. J.; Oh, T.; Old, D. W.; Overman, L. E.; Sharp, M. J. Aza-Cope Rearrangement-Mannich Cyclizations for the Formation of Complex Tricyclic Amines: Stereocontrolled Total Synthesis of $( \pm)$-Gelsemine. J. Am. Chem. Soc. 2005, 127, 18046. (c) Zhou, X.; Xiao, T.; Iwama, Y.; Qin, Y. Biomimetic Total Synthesis of (+)-Gelsemine. Angew. Chem. Int. Ed. 2012, 51, 4909. (d) Chen, X.; Duan, S.; Tao, C.; Zhai, H.; Qiu, F. G. Total Synthesis of $(+)$-Gelsemine via an Organocatalytic Diels-Alder Approach. Nature Commun. 2015, 6, 7204. For the review of total syntheses of gelsemine, see: (e) Lin, H.; Danishefsky, S. J. Gelsemine: A Thought-Provoking Target for Total Synthesis. Angew. Chem. Int. Ed. 2003, 42, 36.

4. (a) Chen, C.-M.; Shiao, H.-Y.; Uang, B.-J.; Hsieh, H.-P. Biomimetic Syntheses of ( \pm )Isopalhinine A, $( \pm)$-Palhinine A, and ( \pm )-Palhinine D. Angew. Chem. Int. Ed. 2018, 57, 15572. (b) Nakhla, M. C.; Cook, C. D.; Wood, J. L. Synthetic Studies Towards ( \pm )Isopalhinine A: Preparation of the Bicyclic Core via Nazarov Cyclization. Tetrahedron Lett. 2021, in press, DOI: 10.1016/j.tetlet.2021.153177.

5. Guo, X.; Li, Y.-Y.; Wang, S.-H.; Zhang, F.-M.; Li, B.-S.; Tu, Y.-Q.; Zhang, X.-M. Construction of the Tetracyclic Core of the Lycopodium Alkaloid Annotinolide C. Org. Chem. Front. 2021, advance article, DOI: 10.1039/d1qo00087j.

6. For a recent review, see: Ghosh, A. K.; Sarkar, A.; Brindisi, M. The Curtius Rearrangement: Mechanistic Insight and Recent Applications in Natural Product Syntheses. Org. Biomol. Chem. 2018, 16, 2006.

7. For the original report of a gold-catalyzed Conia-ene reaction of $\beta$-keto esters, see: (a) Kennedy-Smith, J. J.; Staben, S. T.; Toste, F. D. Gold(I)-Catalyzed Conia-Ene 
Reaction of $\beta$-Ketoesters with Alkynes. J. Am. Chem. Soc. 2004, 126, 4526. For the construction of [3.2.1] bicycle scaffold using gold-catalyzed Conia-ene reaction, see: (b) Barabé, F.; Bétoumay, G.; Bellavance, G.; Barriault, L. Gold-Catalyzed Synthesis of Carbon-Bridged Medium-Sized Rings. Org. Lett. 2009, 11, 4236. (c) Yang, M.; Yin, F.; Snyder, S. A. The Total Synthesis of Chalcitrin. J. Am. Chem. Soc. 2019, 141, 4515. (d) Huwyler, N.; Carreira, E. M. Total Synthesis and Stereochemical Revision of the Chlorinated Sesquiterpene ( \pm )-Gomerone C. Angew. Chem. Int. Ed. 2012, 51, 13066. For a review on Conia-ene and related reactions, see: (e) Hack, D.; Blümel, M. Chauhan, P.; Philipps, A. R.; Enders, D. Catalytic Conia-ene and Related Reactions. Chem. Soc. Rev. 2015, 44, 6059.

8. This strategy reflects quaternary center-based retrosynthetic planning: (a) Hu, P.; Chi, H.; Debacker, K.; Gong, X.; Keim, J.; Hsu, I.; Snyder, S. A. Quaternary-centreguided Synthesis of Complex Polycyclic Terpenes. Nature 2019, 569, 703. (b) Peng, C.; Arya, P.; Zhou, Z.; Snyder S. A. Total Synthesis of (+)-Waihoensene Guided by Quaternary Center Analysis. Angew. Chem. Int. Ed. 2020, 59, 13521.

9. Kippo, T.; Fukuyama, T.; Ryu, I. Regioselective Radical Bromoallylation of Allenes Leading to 2-Bromo-Substituted 1,5-Dienes. Org. Lett. 2011, 13, 3864.

10. Johnson, C. R.; Adams, J. P.; Braun, M. P.; Senanayake, C. B. W.; Wovkulich, P, M.; Uskoković, M. R. Direct $\alpha$-Iodination of Cycloalkenones. Tetrahedron Lett. 1992, 33, 917.

11. Staubitz, A.; Dohle, W.; Knochel, P. Expeditious Functionalization of Quinolines in Positions 2 and 8 via Polyfunctional Aryl- and Heteroarylmagnesium Intermediates. Synthesis 2003, 2, 233.

12. Froissant, J.; Vidal, J.; Guibé-Jampel, E.; Huet, F. Syntheses of Nitrile and Methyl Ester Corresponding to (dl)-Sarkomycin and of Related Compounds. Tetrahedron 1987, 43, 317.

13. Other promoters such as $\operatorname{InCl}_{3}, \mathrm{Mn}(\mathrm{OAc})_{3}$, and $\operatorname{In}(\mathrm{OTf})_{3}$ were screened, but all afforded decomposition products.

14. Shi, L.; Meyer, K.; Greaney, M. F. Synthesis of ( \pm )-Merrilactone A and ( \pm )-Anislactone A. Angew. Chem., Int. Ed. 2010, 49, 9250.

15. Dvorak, C. A.; Schmitz, W. D.; Poon, D. J.; Pryde, D. C.; Lawson, J. P.; Amos, R. A.; Meyers, A. I. The Synthesis of Streptogramin Antibiotics: (-)-Griseoviridin and Its C8 Epimer. Angew. Chem. Int. Ed. 2000, 39, 1664.

16. Adachi, Y.; Kamei, N.; Yokoshima, S.; Fukuyama, T. Total Synthesis of (-)Histrionicotoxin. Org. Lett. 2011, 13, 4446.

17. Yang, C.-G.; Reich, N. W.; Shi, Z.; He, C. Intramolecular Additions of Alcohols and Carboxylic Acids to Inert Olefins Catalyzed by Silver(I) Triflate. Org. Lett. 2005, 7, 4553.

18. Molander, G. A.; St. Jean Jr., D. J. Samarium(II) Iodide-Mediated Intramolecular Conjugate Additions of $\alpha, \beta$-Unsaturated Lactones. J. Org. Chem. 2002, 67, 3861.

19. (a) Ayer, W. A.; Bowman, W. R.; Joseph, T. C.; Smith, P. The Synthesis of $d l-$ Lycopodine. J. Am. Chem. Soc. 1968, 90, 1648. (b) Zhu, Y.; Shao, L.-D.; Deng, Z.-T.; Bao, Y.; Shi, X.; Zhao, Q.-S. PIDA/I $\mathrm{I}_{2}$-Mediated $\alpha$ - and $\beta-\mathrm{C}\left(\mathrm{sp}^{3}\right)-\mathrm{H}$ Bond Dual Functionalization of Tertiary Amines. J. Org. Chem. 2018, 83, 10166. 
20. Pratt, R. C.; Lohmeijer, B. G. G.; Long, D. A.; Waymouth, R. M.; Hedrick, J. L. Triazabicyclodecene: A Simple Bifunctional Organocatalyst for Acyl Transfer and Ring-Opening Polymerization of Cyclic Esters. J. Am. Chem. Soc. 2006, 128, 4556.

21. We also obtained x-ray crystal structures of both $\mathbf{1}$ and 3, further confirming their connectivity. See Supporting Information for details.

22. Ognyanov, V. I.; Hesse, M. Cyclopentenone Annulation of 2-Oxocycloalkane-1carbonitriles. Helv. Chim. Acta. 1987, 70, 1393.

23. Zeng, M.; Murphy, S. K.; Herzon, S. B. Development of a Modular Synthetic Route to (+)-Pleuromutilin, (+)-12-epi-Mutilins, and Related Structures. J. Am. Chem. Soc. 2017, 139, 16377.

24. For asymmetric conjugate cyanide additions onto cyclic, unsaturated ketones, see: (a) Díez, E.; Fernández, R.; Gasch, C.; Lassaletta, J. M.; Llera, J. M.; Martín-Zamora, E.; Vázquez, J. J. Org. Chem. 1997, 62, 5144. (b) Tanaka, Y.; Kanai, M.; Shibasaki, M. A Catalytic Enantioselective Conjugate Addition of Cyanide to Enones. J. Am. Chem. Soc. 2008, 130, 6072. (c) Tanaka, Y.; Kanai, M.; Shibasaki, M. Catalytic Enantioselective Construction of $\beta$-Quaternary Carbons via a Conjugate Addition of Cyanide to $\beta, \beta$ Disubstituted $\alpha, \beta$-Unsaturated Carbonyl Compounds. J. Am. Chem. Soc. 2010, 132, 8862.

25. Nie, W.; Gong, J.; Chen, Z.; Liu, J.; Tian, D.; Song, H.; Liu, X.-Y.; Qin, Y. Enantioselective Total Synthesis of (-)-Arcutinine. J. Am. Chem. Soc. 2019, 141, 9712.

26. Yan, H.-D.; Li, Q.; Wang, Z. Efficient Kinetic Resolution of ( \pm )-Menthol by a Lipase from Thermomyces Lanuginosus. Biotechnol. Appl. Biochem. 2017, 64, 87. 